\title{
РОЛЬ ЦИФРОВЫХ ТЕХНОЛОГИЙ И ИХ ВЛИЯНИЕ НА СОВРЕМЕННУЮ ЛОГИСТИКУ В УСЛОВИЯХ ПАНДЕМИИ
}

Юхновец В.А.,

Полешук Е.Н.

Белорусский государственный экономический университет, г. Минск, Республика Беларусь

Работа посвящена исследованию различий между традииионной $u$ виртуальной цепочками поставок, позволяющая оценить текущее состояние логистических систем компаний. Также рассматриваются основные проблемные моменты функционирования цепей поставок в условиях пандемии.

Ключевые слова: традиционная цепочка поставок, виртуальная цепочка, цифровые технологии, информационная система.

Новый коронавирус, охвативший весь мир, показал, насколько уязвимы международные цепочки поставок. Карантин, блокировки и сокращение грузоперевозок нарушили логистические операции по всему миру.

Безусловно, пандемия влияет на поставки сырья для многих производителей и розничных продавцов во всем мире. Однако более крупные компании, такие как Costco, Walmart и Target, имеют тенденцию быть более устойчивыми из-за своей централизованной стратегии закупок, лучшего контроля запасов и разнообразной базы поставок. Сложившаяся ситуация может стать для них возможностью получить долю на рынке, когда потребители ценят доступность продукта. Для небольших предприятий это может быть очень уязвимым моментом, поскольку накопление запасов приводит к изменчивости их спроса. Малым предприятиям непросто поглотить изменчивость, поскольку у них нет такого масштаба и гибкости, которые необходимы для поддержания разумного уровня доступности продукции в периоды шоков спроса. Одним из способов справиться в такой непростой сложившейся ситуации, повысив при этом эффективность межорганизационной координации может быть переход от традиционных к виртуальным цепям поставок.

Очевидно, что актуальность использования преимуществ цифровых технологий при формировании цепей поставок не вызывает сомнений.

Виртуальные цепи поставок - это не последовательные цепочки, а скорее гибкие сети с быстрой электронной связью в реальном времени. Следовательно, можно дать следующее определение: виртуальная цепь поставок - система, в которой все элементы рационально интегрированы и оптимально функционируют в едином информационном пространстве, созданном с помощью современных информационно-телекоммуникационных технологий [2]. 
Исходя их вышеперечисленных определений схематично традиционную и виртуальную цепи поставок можно представить следующим образом (рис.1).
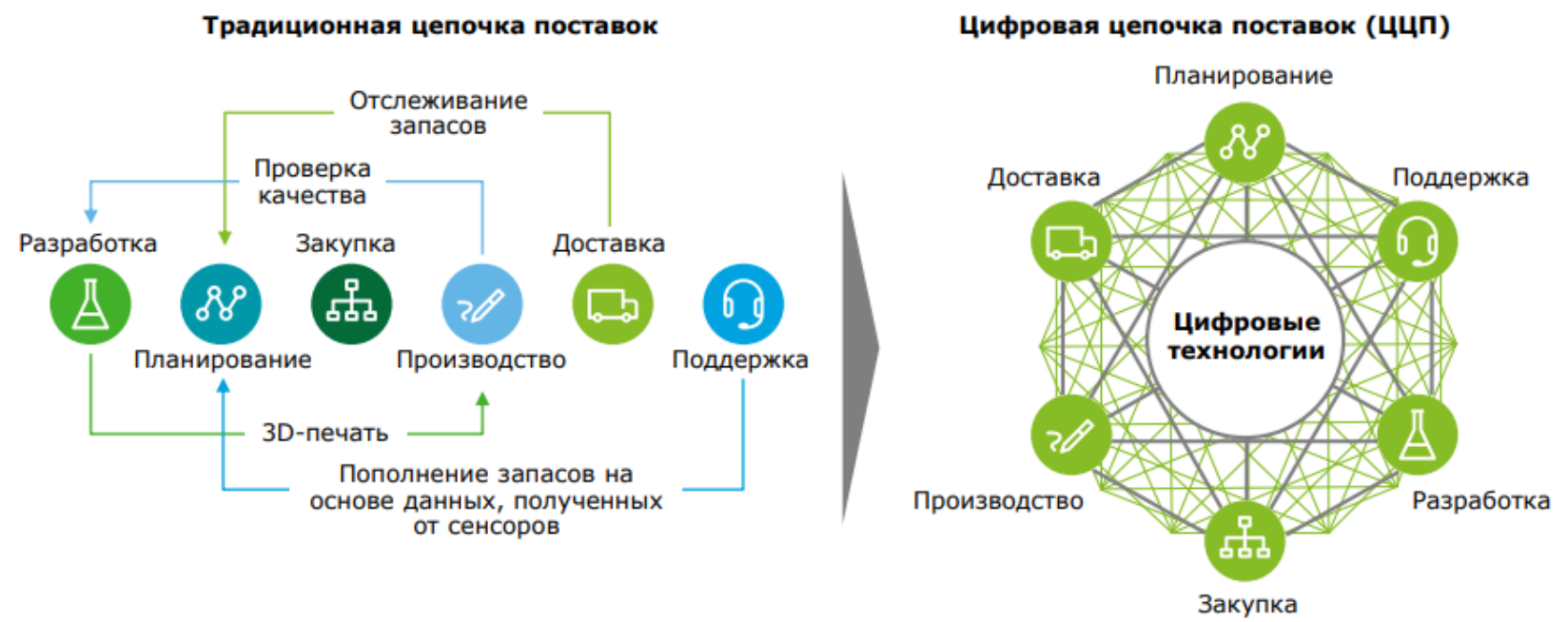

Рис. 1 - Схематичное изображение структуры традиционной и цифровой цепей поставок

Между «традиционными» и виртуальными цепями поставок существуют принципиальные различия, обусловленные характером управления.

Традиционно в цепи поставок передача информации между участками происходит последовательно от одного звена к другому. Поэтому только соседние участники взаимодействуют друг с другом в данном механизме. Например, информация о дефиците товара от покупателей поступает менеджерам торгового зала, далее передается дистрибьютору, потом ее получает предприятие-производитель. В случае необходимости компанияпроизводитель делает запрос поставщику материалов, который, в свою очередь, обращается к заводу-изготовителю, производящему необходимые комплектующие и т.д. В такую цепь поставок включены компании, оказывающие различные услуги, например, складские операторы, перевозчики, страховые компании, брокеры и другие организации, которым также необходимо своевременно получать информацию, чтобы иметь возможность планировать свою работу. Кроме того, все участники цепочки поставок получают только ограниченный объем информации о состоянии материального потока и требованиях к предоставлению необходимых материальных ресурсов и услуг. Ввиду вышесказанного обозначим основные недостатки данного механизма передачи информации:

- информация не передается в полном объеме, происходит ее искажение, наблюдается потеря полноты информации, нарушаются сроки ее поступления;

- обмен информацией между различными подразделениями, работающими в рамках одного бизнес-процесса, не всегда осуществляется в необходимом объеме;

- не существует единой базы данных, содержащей информацию о поставщиках, производителях, ассортименте продукции. 
Еще одна отличительная особенность «традиционной» цепочки поставок заключается в том, что каждый из ее участников ориентируется исключительно на свои интересы, которые определяют их решения относительно структуры производства, управления ресурсами, организации производства и транспорта. Эти решения принимаются в других частях цепи независимо от их влияния на ситуацию. После того, как товары были реализованы своему партнеру, участник традиционной цепочки поставок больше не заботится о дальнейшей судьбе товара. Поэтому можно сделать вывод, что управление в традиционной цепи децентрализовано, а взаимоотношения между ее участниками часто носят конфликтный характер.

В виртуальной цепочке поставок приоритетом управления является оптимизация системы всех ее функций, и координация происходящих в ней процессов. Общие затраты на разработку, закупки, производство, хранение, транспортировку, маркетинг и другие функции, которые реализуются в различных частях цепочки, а также связанные с ними риски учитываются в комплексе и разумно распределяются так, чтобы интересы отдельных участников цепи были согласованы и скоординированы.

Кроме того, особый интерес вызывает изучение и сравнение исследуемых видов цепей поставок по таким параметрам как: выполняемые функции, управление запасами, движение материального и информационного потока, риски, планирование, взаимодействие между участниками (табл. 1).

Таблица 1 - Сравнительная характеристика традиционной и виртуальной цепей поставок

\begin{tabular}{|c|c|c|}
\hline Критерий & Традиционная & Виртуальная \\
\hline $\begin{array}{ll}\text { Материальный } & \text { и } \\
\text { информационные потоки }\end{array}$ & $\begin{array}{l}\text { Движутся } \quad \text { последовательно } \\
\text { от одного звена к другому }\end{array}$ & $\begin{array}{l}\text { Непрерывны и прозрачны } \\
\text { для субъектов управления }\end{array}$ \\
\hline Управление запасами & $\begin{array}{l}\text { Ведется в интересах каждого } \\
\text { отдельного предприятия }\end{array}$ & $\begin{array}{l}\text { Координируется субъектом } \\
\text { управления по всей цепи }\end{array}$ \\
\hline Выполняемые функции & $\begin{array}{l}\text { Определяются } \\
\text { специализацией } \quad \text { каждого } \\
\text { отдельного предприятия и } \\
\text { его интересами }\end{array}$ & $\begin{array}{l}\text { Могут перераспределяться } \\
\text { между участниками исходя } \\
\text { из общих задач цепи } \\
\text { поставок }\end{array}$ \\
\hline Издержки & $\begin{array}{l}\text { Минимизируются каждым } \\
\text { отдельным предприятием в } \\
\text { собственных интересах }\end{array}$ & $\begin{array}{ll}\text { Формируются исходя } & \text { из } \\
\text { максимальной } \\
\text { конкурентоспособности } \\
\text { конечном рынке }\end{array}$ \\
\hline Информация & $\begin{array}{l}\text { Контролируется } \quad \text { каждым } \\
\text { отдельным предприятием }\end{array}$ & $\begin{array}{l}\text { Доступна } \quad \text { для } \quad \text { всех } \\
\text { участников цепи поставок }\end{array}$ \\
\hline Риски & $\begin{array}{l}\text { Сосредоточены в отдельных } \\
\text { предприятиях }\end{array}$ & $\begin{array}{ll}\text { Распределены } & \text { между } \\
\text { участниками цепи }\end{array}$ \\
\hline Планирование & $\begin{array}{l}\text { Ведется в рамках отдельных } \\
\text { предприятий, } \\
\text { преимущественно по схеме } \\
\text { «толкающая» логистика }\end{array}$ & Ведется для всей цепи \\
\hline $\begin{array}{l}\text { Взаимодействие } \\
\text { участниками }\end{array}$ & $\begin{array}{l}\text { Строится для достижения } \\
\text { отдельными предприятиями } \\
\text { собственных цепей }\end{array}$ & \begin{tabular}{lcrr} 
Строится для & \multicolumn{2}{l}{ достижения } \\
целей & всей & цепи \\
конечном рынке &
\end{tabular} \\
\hline
\end{tabular}


Следовательно, переход от «традиционных» к современным цифровым цепочкам поставок - это, прежде всего, переход от локальных решений, которые каждый участник цепочки принимает в своих интересах к единому управлению, чтобы повысить конкурентоспособность всей цепочки поставок, всех находящихся в отношениях и связях субъектов хозяйствования. Следовательно, самым большим препятствием на пути к успеху, особенно для малых и средних предприятий, будет отсутствие цифровой культуры, а также готовность принять не только новые технологии, но и новое технологическое мышление.

\section{Список литературы}

1 Кристофер М. Логистика и управление цепями поставок / М.Кристофер; под общ. Ред. В.С.Лукинского - СПб.: Питер, 2004. - 316 с.

2 Свободная энциклопедия Википедия / Виртуальная логистика / Терминология виртуальной логистики / [Электронный ресурс] // Режим доступа: https://ru.wikipedia.org/wiki. - Дата доступа: 25.02.2020. 